

\section{ABSTRACT}

The Project entitled "Women's Inclusion in Science and Technology" is focused on basic education in order to provide elements for more women to access certain areas of knowledge and, consequently, the job market where they are minority. The goals are to encourage and support girls from public and private schools in the countryside of Minas Gerais State in Brazil to pursue a career in Science, Technology, Engineering and Mathematics (STEM). Its achievement is sustained in the dissemination of areas of knowledge and career possibilities for the female, focusing on those where they are minority. The methodology is based on discussions, dynamics and workshops with several themes involving Mathematics, Physics, Chemistry, Astronomy, Neurosciences and Robotics, with the support of renowned professionals from the public and private sector acting as role models. During the discussions, issues related to women's rights, maternity, family, and the exchange of personal experiences were discussed. In this paper, the results of this project in the year 2012, 2013 and 2016 are presented, showing the lack of interest of the students in subjects considered as "hard" and in so-called masculine professions, the lack of affinity with the teachers of these subjects, and also showing the influence of society's gender stereotypes on career choice.

Keywords: Science. Gender. Education.

\section{INTRODUÇÃO}

Até o início do século XX, as Ciências eram culturalmente definidas como atividades impróprias para as mulheres. Entretanto, sempre houve aquelas que, apesar dos obstáculos como a discriminação sexual, o reduzido número de mulheres em cargos de liderança, recebimento de menores salários que o sexo masculino, tarefas do lar e maternidade sendo atribuídas exclusivamente a elas, ainda assim optaram por segui-las (LINS; MACHADO; ESCOURA, 2016).

Como um dos destaques, podemos citar Marie Curie, que em 1903 ganhou o prêmio Nobel em Física e em 1911 o prêmio Nobel em Química, tornando-se a única pessoa a receber uma segunda premiação. Contudo, ainda assim não pode ingressar na Academia de Ciências da França por ter uma possível ascendência judia, mas principalmente por ser mulher, mostrando a resistência da sociedade ao ingresso delas nas Ciências (SILVA; RIBEIRO, 2011).

A participação igualitária de mulheres e homens nas Ciências não é importante apenas por ser uma questão de justiça. Estudos mostram que a visão do mundo das mulheres é diferente da dos homens, levando a questionamentos 
científicos diferentes, além de serem mais cuidadosas e atentas nas pesquisas (CRUZ, 2007).

Frequentemente é retratado que cientistas do sexo feminino tem menor desempenho e produtividade quando comparadas a cientistas do sexo masculino (LETA, 2003). Além disso, devido à construção histórica, social e cultural, há concentração dos homens nas áreas exatas, e de mulheres nas áreas humanas e sociais, levando a uma baixa representatividade feminina nesses setores.

Borges (2014) destaca alguns fatores que levam a essa tendência de polarização em determinadas áreas: (a) falta de incentivo e orientação da família e da escola no sentido de motivar as meninas para áreas das Ciências e Tecnologia, além de (b) falta de contato com atividades de cunho tecnológico nas escolas, conduzindo-as na escolha por profissões estereotipadas como femininas. É observado no ambiente escolar que quando os meninos são motivados nas áreas exatas as meninas passam a ver as "profissões masculinas" de difícil acesso ou desinteressantes.

Para Chassot (2003, citado por BORGES, 2014), ao longo de milênios as mulheres foram excluídas e invisibilizadas de atividades científicas, e há cerca de duas ou três gerações que o perfil das Ciências começou a mudar lentamente.

Dados do INEP - Instituto Nacional de Estudos e Pesquisas Educacionais apontam que, nos anos de 2012 e 2013, o número de mulheres que ingressaram e concluíram a educação superior no Brasil foi maior que o número de homens. Porém, ao se analisar a preferência dos cursos, vemos que o gênero feminino fica concentrado nas áreas de humanas e saúde, enquanto o masculino está ligado a áreas das Exatas e cursos relacionados à Tecnologia e Computação (MATTOS; SILVA; MOREIRA, 2015).

Além do baixo ingresso de mulheres nos cursos das Ciências Exatas, Engenharias e Computação, elas também diminuem sua participação à medida que avançam nas suas carreiras, o chamado "Efeito Tesoura”. Por exemplo, no Brasil, cerca de $30 \%$ dos ingressantes do curso de Física são mulheres. Este número diminui para $20 \%$ durante o doutorado e mestrado e se reduz para $15 \%$ entre as docentes brasileiras. Este fenômeno ocorre também em todo o mundo (BRITO; PAVANI; JR, 2015).

No que se refere ao mercado de trabalho, em 2005, o Fórum Econômico Mundial divulgou um relatório sobre as diferenças de gênero com dados de 58 países mais desenvolvidos economicamente, incluindo o Brasil. Foram abordadas a participação econômica, oportunidade econômica (ambos relacionados à par- 
ticipação feminina no mercado de trabalho e remuneração igualitária), empoderamento político, conquistas educacionais, saúde e bem-estar. A conclusão foi de que nenhum país analisado conseguiu avançar na diminuição de disparidades dos gêneros, e um dos resultados foi de que as mulheres ainda ganham $78 \%$ menos que os homens exercendo a mesma função (BORGES, 2014).

Outro ponto que merece ser destacado é o Prêmio Nobel concedido a cientistas cujos trabalhos permitiram um avanço tecnológico e científico para a humanidade. Percebemos que as mulheres possuem uma representatividade extremamente baixa, principalmente na categoria de Física e Química.

Figura 1 - Distribuição dos Prêmios Nobel concedidos somente às mulheres (Figura a) e a homens e mulheres juntos (Figura b) para todas as categorias, no período de 1901 a 2016. Fonte: Dados fornecidos pelo site do Prêmio Nobel.

\section{Prêmio Nobel concedido até 2016 às}

\section{9 mulheres}

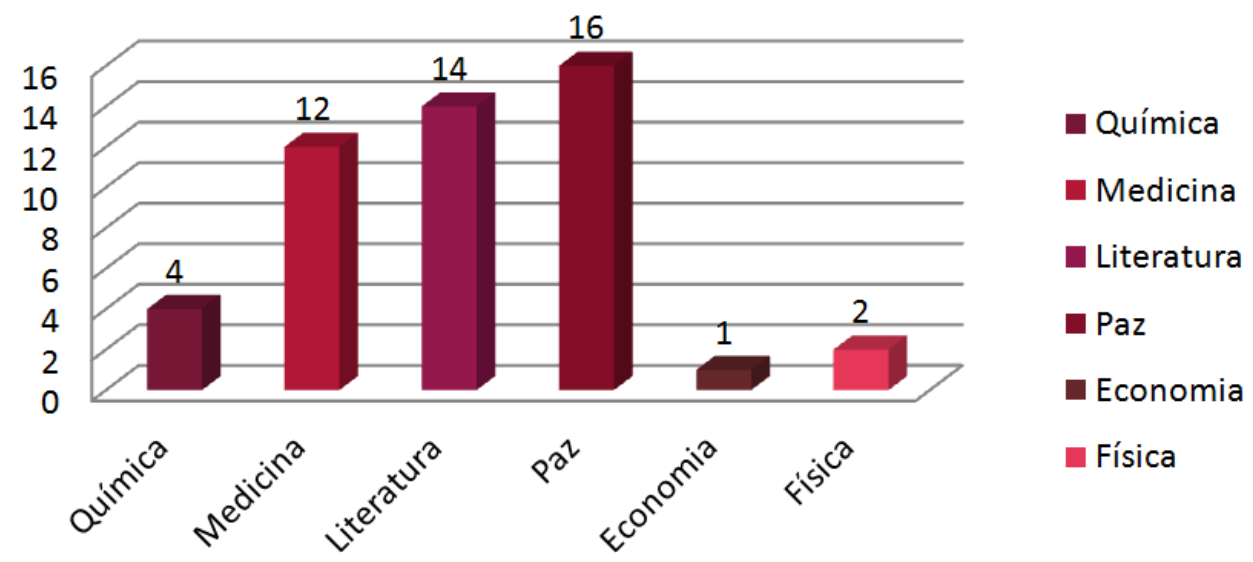

Prêmio Nobel concedido até 2016

(911 prêmios)

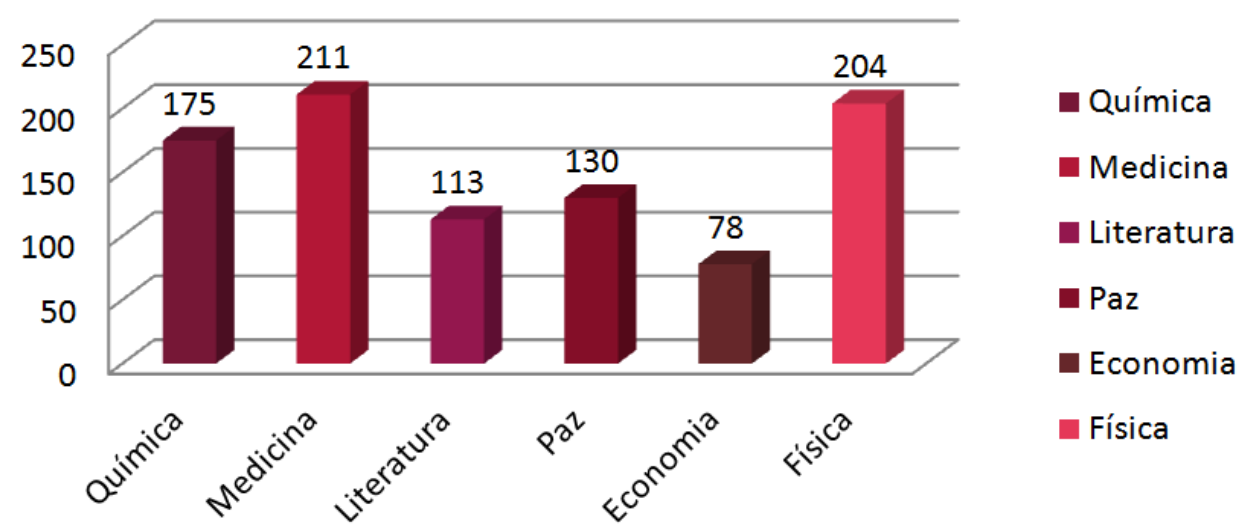


A Figura 1 revela que $62 \%$ dos prêmios concedidos pelas mulheres correspondem às áreas de Humanidade (Literatura e Paz). A última vez em que uma mulher ganhou o Nobel de Física foi em 1963, pela pesquisa de Maria Goeppert Mayer. No total de todas as categorias, as mulheres correspondem a menos de 5,4\%, desde quando o prêmio foi criado em 1901 (PRÊMIO NOBEL, 2017).

Diversas políticas públicas no Brasil e no mundo têm sido lançadas buscando a mudança desse cenário, objetivando o incentivo e motivação de meninas para a Ciência, Tecnologia, Engenharia e Matemática.

\section{AÇÕES VOLTADAS PARA A EDUCAÇÃO BÁSICA}

O projeto "Inclusão das Mulheres nas Ciências e Tecnologia (IMCT)" foi criado no sentido de promover ações que visam, não somente fomentar a igualdade de gênero, mas também a possibilitar maior aproveitamento da capacidade intelectual mundial, atualmente desperdiçada, promover o enriquecimento da produtividade científica e tecnológica (através de uma diversidade de pensamentos e inovações vistas sob diferentes perspectivas).

Sua atuação se fundamenta em ações na educação básica, visando a um aumento no ingresso de mulheres em áreas predominantemente masculinas, reforçando a autoconfiança das participantes, principalmente daquelas que vivem em meios com poucas influências positivas e classes mais carentes financeiramente.

Os dados obtidos nesse estudo foram analisados de forma quantitativa através de questionários respondidos por 679 meninas (11 a 16 anos de idade) de escolas públicas e particulares das cidades de Ouro Branco e Congonhas (interior de Minas Gerais) nos anos de 2012, 2013 e 2016 (Tabela 1). Foram igualmente usadas neste trabalho as falas espontâneas e análise de desenhos feitas pelas participantes, bem como as observações visuais dos comportamentos das meninas durantes as ações, registradas pelos(as) bolsistas e voluntários(as) do projeto.

A metodologia utilizada consistiu em duas a quatro visitas nas escolas participantes (em horário de aula) e um workshop realizado no Campus Alto Paraopeba da UFSJ, em parceria com a ONG internacional Greenlight for Girls, sediada em Bruxelas - Bélgica (movimento mundial idealizado por uma Engenheira de Produção, Melissa Rancourt, que conjuga do mesmo objetivo deste projeto: divulgação e apoio a meninas para as áreas das Ciências, Tecnologia, Engenharia e Matemática).

Na primeira visita (denominada Sondagem) um questionário foi usado para quantificar dados das jovens participantes, relacionados a matérias favo- 
ritas, renda, raça, profissão do futuro, professores com mais e menos afinidades, incentivo ou não da escola e dos pais para o ingresso em uma universidade e o apoio dos pais na profissão desejada. Em seguida, foi apresentada a segunda atividade denominada Dinâmica das Profissões, apresentação e discussão do tema e objetivo do projeto. Na Dinâmica das Profissões, foi solicitado para que as meninas desenhassem pessoas que exerciam certas profissões, a saber, Enfermagem, Engenharia, Medicina e Taxista, além de atribuir características necessárias para exercer cada atividade. Tomou-se cuidado para que o gênero não fosse especificado durante a fala da bolsista, para não influenciar no resultado. Essa atividade foi importante para compreender como os estereótipos de gênero estão ligados às profissões.

As visitas seguintes consistiram em oficinas de 50 minutos abordando experimentos de Física e Química (eletrostática, pressão, empuxo, densidade, ondas, tensão superficial, ácido/base e termodinâmica). As meninas foram divididas em grupos, para que pudessem realizar e discutir cada experimento, levantando questionamentos e apresentando suas ideias para a bolsista e voluntárias do projeto. Os materiais necessários eram disponibilizados para as meninas, para que pudessem vivenciar a experiência de todos os fenômenos apresentados.

Não houve nenhum processo de seleção para as alunas, a participação foi voluntária.

\section{RESULTADOS}

\section{OS DESENHOS}

Os resultados desta dinâmica foi baseada em dados obtidos das escolas públicas (municipais e estaduais) em 2016, devido a não disponibilidade das es-

Tabela 1 - Relação do número de alunas e escolas participantes por ano de atuação no projeto.

\begin{tabular}{|c|c|c|c|}
\hline & 2012 & 2013 & 2016 \\
\hline Número de alunas assisitidas de escolas particulares & 0 & 66 & 0 \\
\hline $\begin{array}{l}\text { Número de alunas assistidas de escolas públicas } \\
\text { (municipal e estadual) }\end{array}$ & 121 & 212 & 258 \\
\hline Número de alunas assistidas do Ensino Fundamental & 121 & 183 & 258 \\
\hline $\begin{array}{l}\text { Número de alunas assistidas do Ensino Médio (Particular e Institu- } \\
\text { tos Federais) }\end{array}$ & 0 & 95 & 22 \\
\hline Total & 121 & 278 & 280 \\
\hline $\begin{array}{l}\text { Número de escolas públicas } \\
\text { (municipal e estadual, Institutos Federais) }\end{array}$ & 3 & 6 & 6 \\
\hline Número de escolas particulares & 0 & 2 & 0 \\
\hline Total & 3 & 8 & 6 \\
\hline \multicolumn{4}{|c|}{ Fonte: Dados fornecidos pela coordenação do projeto IMCT. } \\
\hline
\end{tabular}


colas particulares para as ações previstas neste projeto. Para uma delas, a justificativa que foi apresentada é que "o plano pedagógico do ano já está pronto. As meninas já tem uma profissão definida e estão se preparando para o ENEM - Exame Nacional do Ensino Médio".

A Dinâmica das Profissões evidenciou como os estereótipos de gênero influenciam as meninas ao desenharem e atribuírem características às profissões. Personalidades relacionadas ao cuidado, zelo, paciência, atenção, gentileza, que são comportamentos popularmente associados às mulheres, estiveram presentes em $89 \%$ das características de pessoas que exerciam a profissão de enfermagem. As participantes desenharam enfermeiras para esse cargo (Fig. 2).

Um comportamento diferente foi notado para pessoas que faziam medicina (Fig. 3). As participantes atribuíram as mesmas "características femininas", porém desenharam médicos (gênero masculino). Evidenciando, o produto da história e da educação em nossa sociedade, onde vemos a dificuldade de meninas atribuírem essa profissão a alguém que seja do mesmo gênero que elas.

Para a engenharia, $82 \%$ das participantes desenharam homens, e as características citadas foram "ser bom de cálculo, gostar de Matemática, habilidoso, esperto, inteligente", o que mais uma vez afirmou a barreira entre a área das Exatas e o gênero feminino (Figura 4). Esse cenário tem sido mudado lentamente, no entanto é necessário ainda políticas públicas e projetos que trabalhem com igualdade de gênero.

Toda vez que uma menina tem menos incentivo para fazer algo considerado como masculino, os estereótipos de gênero funcionam como um freio para todas as possibilidades de aprendizagem que poderiam levá-la a um outro futuro. Além disso, essas diferenças entre comportamento feminino e masculino criam desigualdades e hierarquização, como desvalorização salarial, repressões e violências, temas que têm levado à mobilizações de movimentos reivindicatórios, lutas e disputas por igualdade (LINS; MACHADO; ESCOURA, 2016).

Segundo Finco (2003), as crianças na educação infantil não possuem práticas sexistas em suas brincadeiras e comportamentos. Elas as vão adquirindo a medida que permanecem na escola. O estereótipo de "coisas de meninos" e "coisas de meninas" são comportamentos provenientes de adultos, e que acabam influenciando crianças na sua infância. Finco (2008) cita que características físicas e comportamentos esperados para meninos e meninas são reforçados no dia-a-dia na educação infantil. O que é valorizado para a menina não é muitas vezes apreciado no menino e vice-versa.

A discussão das questões de gênero na infância possibilita uma educação mais igualitária, que respeite a construção da identidade da criança, não a limi- 
Figura 2 - Desenhos das participantes (2016) para a alguém que executa enfermagem, como profissão.

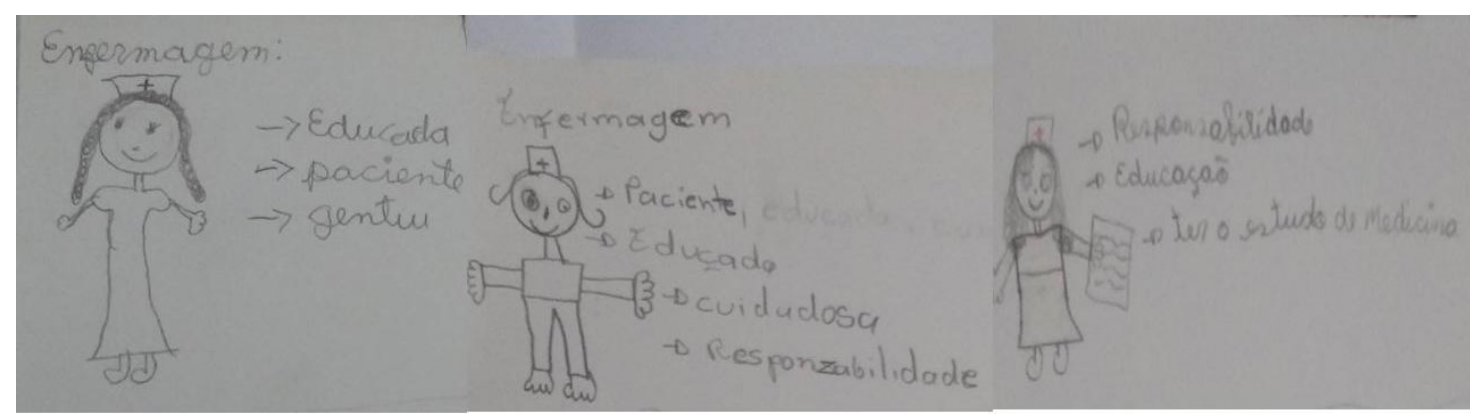

Fonte: Desenhos fornecidos pela coordenação do projeto IMCT.

Figura 3 - Desenhos das participantes (2016) para a alguém que executa medicina, como profissão.

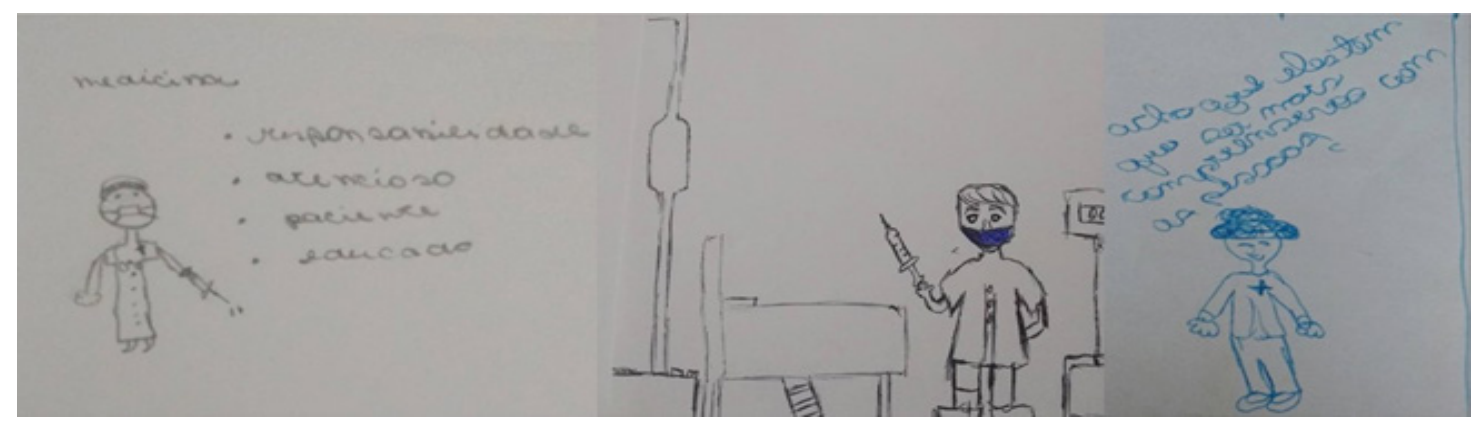

Fonte: Desenhos fornecidos pela coordenação do projeto IMCT.

Figura 4 - Desenhos das participantes para a alguém que executa engenharia, como profissão.

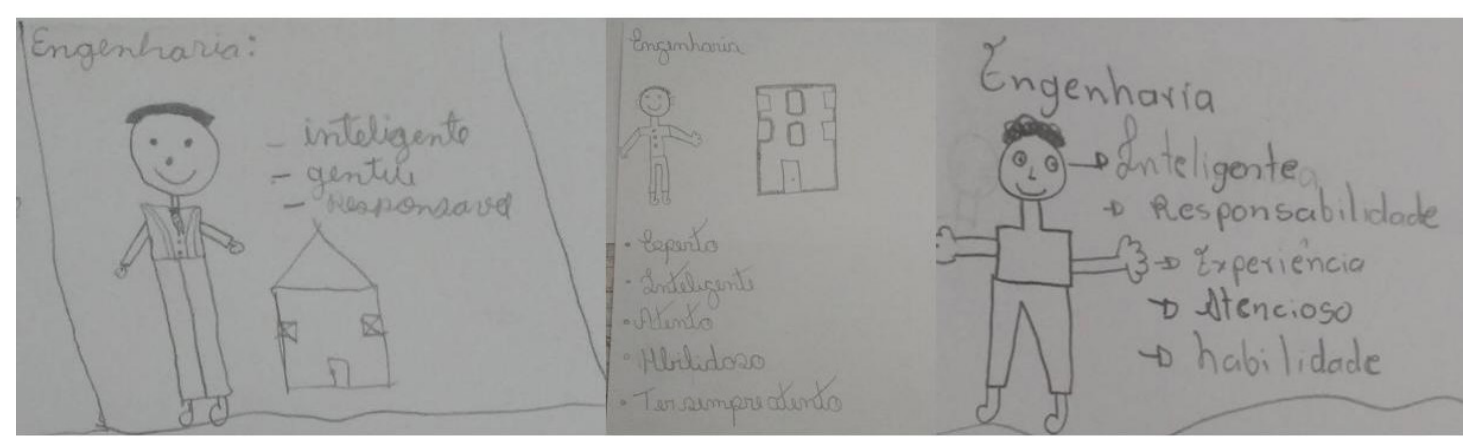

Fonte: Desenhos fornecidos pela coordenação do projeto IMCT. 
tando. Cabe então, uma mudança de comportamento na sociedade, na escola e na família, permititindo que as crianças cresçam sem essas imposições.

Seguida da Dinâmica dos Desenhos, foram realizadas discussões com as meninas, mostrando que existem mulheres que gostam das exatas e são engenheiras, bem como homens que são enfermeiros, não existindo profissões ou comportamentos que devam ser generalizados como características de um único sexo.

As participantes concordaram e citaram situações em que foram repreendidas por terem "comportamentos masculinos", como exemplificado abaixo:

\begin{abstract}
Uma vez eu fui para a casa do meu pai e eu comentei com ele que desde pequena gostaria de fazer biologia marinha, ele não gostou e disse que lugar de mulher é arrumar casa e ficando dentro de casa. Eu sai chorando e minha mãe falou que não era pra mim ligar e que eu poderia fazer o que eu quisesse, desde que eu seja feliz e tenha boas atitudes. (Estudante 1, 11 anos, 2016).

Acho que as mulheres têm que ter os mesmos direitos que os homens. Muitos dizem que a mulher é fraca, delicada e não pode liderar um grupo, como na política. Muitas pessoas criticam quando uma menina quer jogar futebol ou brincar com carrinhos e falam que só meninos fazem isso e você não pode porque é menina. (Estudante 2, 12 anos, 2016)
\end{abstract}

\title{
O QUESTIONÁRIO
}

A partir das análises realizadas nas fichas avaliativas, concluímos que de um total de 278 alunas entrevistadas em 2013, 81\% gostam de estudar Matemática na escola. Assim, percebemos que existe o interesse do público feminino sobre essa matéria. Contudo, $77 \%$ das entrevistadas acreditam que a razão de tão poucas mulheres se ingressarem nas áreas das ciências, matemáticas e engenharias são: a falta de oportunidade e informação, constituir áreas predominantemente masculinas, existir dificuldades para entrar no mercado de trabalho, além de se considerarem incapazes e que os homens possuem maior facilidade para aprendizagem.

Em 2016, o quadro relatado acima se revela novamente. As entrevistadas afirmaram desinteresse para as disciplinas das Exatas, alegando "não somos boas em Matemática, a matéria é chata, os meninos são melhores, não consigo entender a explicação". No entanto, havia aquelas que gostavam destas disciplinas, levando uma boa discussão sobre o tema e a desconstrução desses conceitos ("discrimatórios") das colegas. A disciplina que mais apreciam para este grupo é Português (19,8\%), seguida de Matemática (17,4\% - apesar das críticas) e de Biologia (13\%), vide Figura 5. A grande maioria revela interesse pelas Humanas (74\%). 
Os resultados acima estão em acordo com o publicado por Soares (SOARES, 2001) que aponta que adolescentes do sexo feminino possuem uma menor expectativa do sucesso profissional em áreas da Ciência e Tecnologia e consequentemente se tornam profissionais menos confiantes, por subestimarem suas habilidades.

Figura 5 - Disciplinas preferidas pelas participantes (2016).

\section{DISCIPLINAS QUE MAIS GOSTAM}

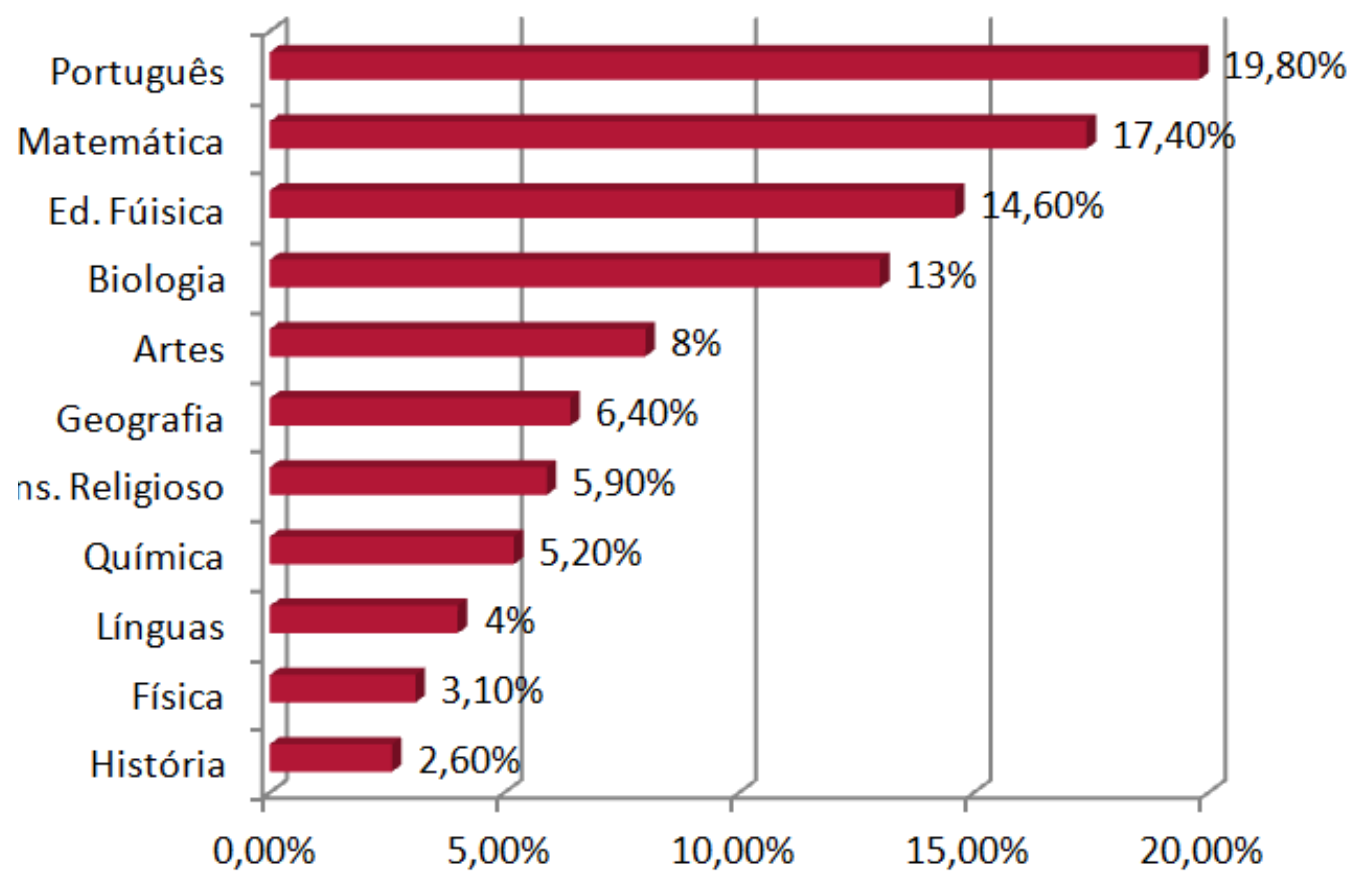

Porcentagem

Fonte: Dados fornecidos pela coordenação do projeto IMCT.

Os dados coletados em 2016 evidenciam a correlação existente entre a disciplina e o professor que a leciona (Tab. 2). Um estudo realizado em Pernambuco com estudantes de escolas públicas e particulares, mostra que estas caracterizaram os professores de Matemática como inteligente, louco, doido, anti-social, distante dos alunos, estudioso e com superioridade (CRUZ; MAIA, 2011). Já os professores das Humanas e Biologia eram caracterizados como pacientes, compreensivos, amigos e abertos. Pesquisas mostram que a identificação com o (a) professor (a) pode influenciar no vínculo com as disciplinas e as motivações para a escolha do curso superior (QUEIROZ; CARVALHO; MOREIRA, 2014).

Mediante a baixa identificação das estudantes participantes com as disciplinas das Exatas e a concepção de que os homens são melhores em cálculos, levaram-nas a escolhas de cursos superiores considerados popularmente como "femininos", relacionados a Humanidades ou ao cuidado, como Medicina, Enfermagem, Estética, Odontologia e Pedagogia, que são associados a tarefas supos- 
tamente exercidas pelas mulheres no âmbito privado, nos cuidados com a família e com a casa (Tab. 3). Das alunas entrevistadas, apenas $1,8 \%$ declaram desejar um futuro profissonal na área da Matemática e Ciências da Natureza

Tabela 2 - Características dos professores em suas disciplinas, apontadas por alunas (22) do ensino médio de uma escola pública (Instituto Federal) em 2016.

\begin{tabular}{|l|c|l|}
\hline \multicolumn{1}{|c|}{$\begin{array}{c}\text { Disciplinas que } \\
\text { se identificam }\end{array}$} & $\%$ & \multicolumn{1}{c|}{ Observação } \\
\hline Português & 36 & $\begin{array}{l}\text { Ótima professora, gosto dela, gosta do que } \\
\text { faz, me incentivou, próximo dos alunos, não } \\
\text { é tão rígida, a que mais admiro }\end{array}$ \\
\hline Ed. Física & 23 & $\begin{array}{l}\text { Bom professor, legal, admiro, aberto para os } \\
\text { alunos }\end{array}$ \\
\hline Biologia & 18 & $\begin{array}{l}\text { É engraçado, prende nossa atenção, ótima } \\
\text { pessoa }\end{array}$ \\
\hline Química & 9 & Ensina bem \\
\hline Filosofia & 5 & Senso de humor \\
\hline Matemática & 5 & - \\
\hline Disciplinas que & $\%$ & \\
\hline Tratamento (Cálculo) & 18 & Não entendo; difícil compreensão \\
\hline Lavra, serviços e equipamentos & 14 & Não é aberto; \\
\hline Português & 25 & Críticas, não aceita discussões \\
\hline Física & 14 & Não entendo explicação \\
\hline Matemática & 9 & Não entendo explicação \\
\hline \multicolumn{2}{|c|}{ Fonte: Dados fornecidos pela coordenação do projeto IMCT } \\
\hline
\end{tabular}


Tabela 3 - Profissões escolhidas pelas participantes e suas respectivas áreas, em ordem crescente de preferência (de cima para baixo).

\begin{tabular}{|l|c|}
\hline \multicolumn{1}{|c|}{ Profissão por área do conhecimento } & $\%$ \\
\hline $\begin{array}{l}\text { Matemática e Ciências da Natureza } \\
\text { Física; Química; Matemática; Astronomia }\end{array}$ & $\mathbf{1 , 8}$ \\
\hline $\begin{array}{l}\text { Ciências Humanas } \\
\text { Psicologia, Pedagogia }\end{array}$ & $\mathbf{4 , 2}$ \\
\hline $\begin{array}{l}\text { Ciências Agronômicas e Veterinárias } \\
\text { Medicina Veterinátia e Agronomia }\end{array}$ & $\mathbf{5 , 0}$ \\
\hline $\begin{array}{l}\text { Ciências Sociais Aplicadas } \\
\text { Administração; Arquitetura; Design; Economia; Direito; Publicidade }\end{array}$ & $\mathbf{2 6 , 8}$ \\
\hline Engenharias e Ciências da Computação & $\mathbf{1 8 , 0}$ \\
\hline $\begin{array}{l}\text { Ciências da Saúde } \\
\text { Enfermagem; Medicina; Nutrição; Odontologia }\end{array}$ & $\mathbf{2 9 , 7}$ \\
\hline $\begin{array}{l}\text { Outras } \\
\text { Estilista; Atriz; Modelo; Fotógrafa; Artes Cênicas; Gastronomia }\end{array}$ & $\mathbf{1 3 , 8}$ \\
\hline Não sei & $\mathbf{0 , 7}$ \\
\hline \multicolumn{1}{|c|}{} & \\
\hline
\end{tabular}

No entanto, havia aquelas que identificavam e desejavam um futuro profissonal a área das Ciências, Tecnologia, Engenharia e Matemática:

Vou seguir meu sonho de ser Engenheira. Não tô nem aí pros homens. (Estudante 3, 12 anos, 2016)

Seja você sem se preocupar com o que a sociedade quer que você seja. Como uma pergunta que eu sempre faço a todos "você pensa assim porque quer ou por que é assim que a sociedade quer que você pense? (Estudante 4, 13 anos, 2016).

É importante citar também as falas desestimulantes de professores(as) relatadas nos questionários:

Minha professora do ano passado me disse que o lugar de mulher é em casa. Na minha opinião, as mulheres têm que ter um trabalho para se sentir independente. (Estudante 5, 11 anos, 2016)

Minha professora disse que odontologia é melhor para o homem, não para a mulher. (Estudante 6, 11 anos, 2016)

Meu professor de Ciências não acredita que mulheres fazem parte da sociedade". (Estudante 7, 13 anos, 2016) 
É recomendável que falas, que designam diferenças de gênero, sejam extintas do ambiente escolar e substituídas por atividades que desconstruam esses tipos de estereótipos, como os relatos acima pelas meninas.

\section{AS OFICINAS}

Nas oficinas, as meninas puderam vivenciar fenômenos vistos teoricamente na escola, instigando então sua curiosidade. No começo estavam tímidas, dando poucas explicações sobre os experimentos. Com o tempo, a timidez foi dando espaço à curiosidade, e todas se envolviam nas oficinas. Após a perda da timidez, todas se divertiam bastante, agindo com descontração e com muita interação com a bolsista e as voluntárias (Fig. 7). Havia algumas poucas meninas que, por gostarem das Exatas, sabiam logo as explicações, e eram então alvo de brincadeiras das amigas, como se fosse estranho elas se interessarem pela área.

Durante os experimentos, sempre foram expostas as situações do cotidiano, para que pudessem ver como as Ciências estão sempre presentes no dia a dia. Nas oficinas, eram frequentes as falas de que elas iriam repetir a experiência em casa para os familiares conhecerem também.

Adorei as oficinas, e espero que [...] [bolsistas]voltem. (Estudante 8, 14 anos, 2016).

Figura 7 - Visitas do IMCT à E. M. Pio XII (a) e E. E. Levindo Costa Carvalho em 2016 (b).

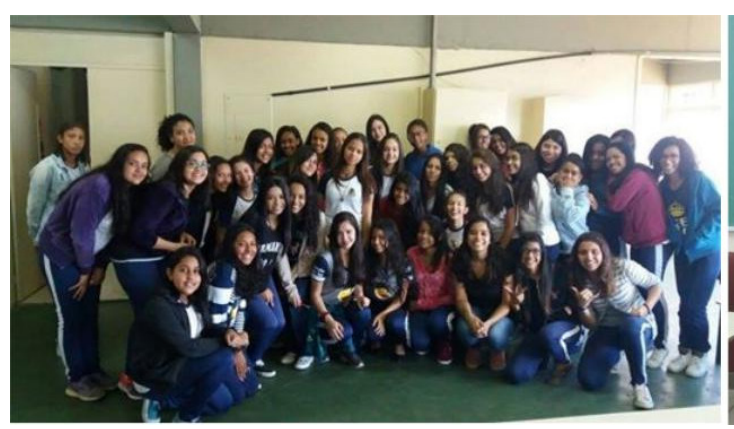

(a)

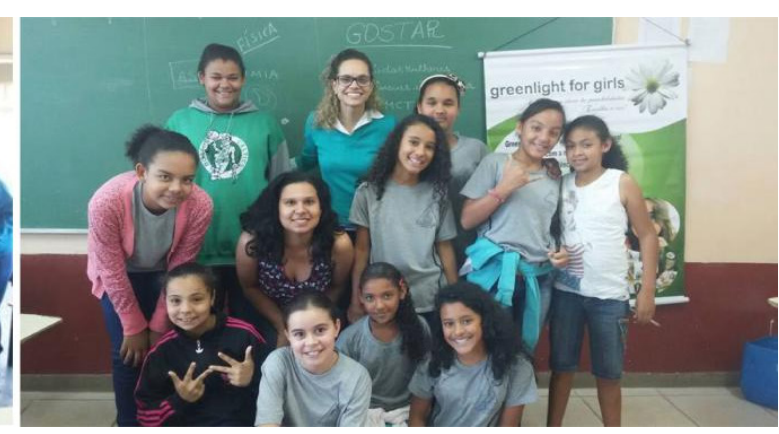

(b)

Fonte: Fotografia retirada pelos integrantes do projeto IMCT.

\section{GREENLIGHT FOR GIRLS IN BRAZIL}

Os workshops Greenlight for Girls in Brazil constituem uma das ações previstas no projeto IMCT. É o momento mais esperado pelas meninas, onde passarão momentos com pesquisadoras das universidades brasileiras, a presidente da ONG Greenlight for Girls (Melissa Rancourt - Bélgica) e alunas de Engenharia do Campus (de Bioprocessos, Civil, Mecatrônica, de Telecomunicações e Química). A primeira edição ocorreu em 2012, a segunda em 2013 e a terceira em 2016, nas instalações do Campus Alto Paraopeba da UFSJ em Ouro Branco - MG. 


\section{PALESTRA PARA OS PAIS}

Nos dados analisados em 2013, ficou evidente a forte influência dos pais quanto à escolha da profissão de suas filhas. Ao perguntar qual profissão elas se veem no futuro, (Fig. 8a) a grande maioria afirmou Engenharia. Contudo, quando interrogadas sobre o que seus pais gostariam que elas escolhessem como profissão, elas responderam em sua maioria, Medicina (Fig. 8b). Curiosamente, das entrevistadas, $71 \%$ concordam com a opinião de seus pais, declarando que eles (os pais) sabem o que é "melhor para elas". Esse fato indica a influência dos pais nas decisões de suas filhas, que acabam por optar por outra área que não seja as Exatas, ou "mais adequada para uma moça". Andrade (1997) discute sobre a influência dos pais, apontando que a transmissão de conceitos, mitos e valores familiares podem influenciar na profissão do(a) filho(a) chegando a ser impeditiva de um processo de escolha autônomo.

Figura 8: Preferência das meninas por certas profissões (Gráfico a) versus o que seus pais desejariam que elas seguissem (Gráfico b), para os anos de 2012 e 2013.

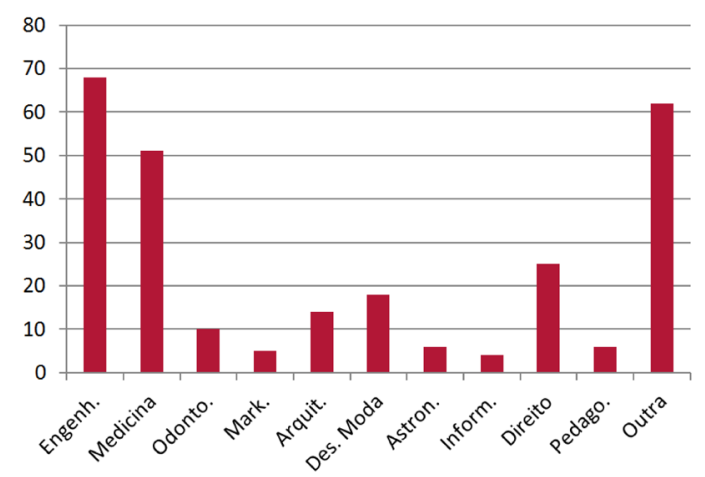

(a)

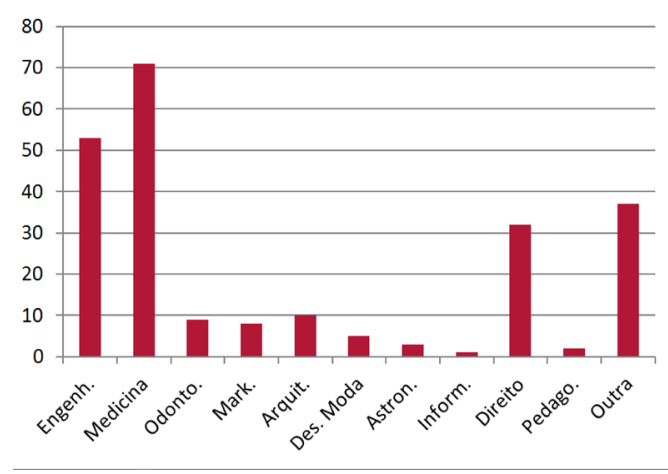

(b)

Fonte: Dados fornecidos pela coordenação do projeto IMCT.

Nesta perspectiva, o projeto sentiu a necessidade de atuar junto aos pais. O processo de manifestação desta ação foi demorado, requerendo maturidade para tratar deste assunto de forma a não causar desconforto para os mesmos. Neste aspecto, através do apoio de uma escola municipal de Congonhas (2016) o projeto promoveu duas palestras, durante uma reunião rotineira de pais. A palestra teve como objetivo mostrar aos responsáveis o objetivo do projeto, apresentação dos resultados das fichas de avaliação, convite para reflexão quanto ao apoio destinado as suas filhas na escolha de suas carreiras e falas limitadoras do nosso cotidiano que poderiam promover a desigualdade e preconceito contra a escolha de determinadas carreiras pelas meninas.

No momento das perguntas, alguns pais demostraram sua preocupação em como auxiliar suas filhas e outros (pais de meninos) o receio de que o projeto tivesse a conotação de ideologia de gênero. Neste momento, pareceu que seria 
mais fácil aceitar que meninas desempenhassem atividades masculinas, que o contrário.

Reconhece-se que o assunto é delicado para os pais, mas necessário, de forma que a palestra foi elogiada pela direção da escola. Vale lembrar que esta escola tem um diferencial com relação as outras por já apresentar projetos internos voltados para a igualdade de gênero, o que estreitou mais ainda a relação com a mesma, no sentido de um trabalho mais sólido e eficaz.

Duas palestras de conscientização foram também proferidas pela coordenadora do projeto IMCT, para professores da rede municipal de Ouro Branco, em 2016.

\section{CONSIDERAÇÕES FINAIS}

Através desse trabalho, pode-se compreender as relações de gênero das estudantes de escolas públicas e particulares, além de analisar aspectos que as levam ao afastamento das áreas das Exatas. O estudo mostrou que as participantes sofrem a influência dos estereótipos de gênero de nossa sociedade (família, escola, comunidade, mídia, etc), dificultando o interesse por matérias das Exatas e por um futuro profissional nessa área.

O projeto se mostrou como uma excelente forma de despertar o interesse das estudantes por áreas predominantemente masculinas. Pode trabalhar de uma forma sútil as diferenças de gênero tanto no mercado de trabalho, quanto na família, profissões, "atividades de meninos e meninas", buscando a promoção a longo prazo, da diminuição dessas diferenças.

Acredita-se que essas ações possam fortalecer a imagem de que as áreas das Ciências, Tecnologia, Engenharia e Matemática devam também ser atuadas pelas mulheres, possibilitando um novo olhar científico que promova o enriquecimento da produtividade científica e tecnológica.

Os resultados das ações deste projeto levam a crer que o fator cultural também tem afetado na escolha da profissão. Como vivemos em uma sociedade em que a mulher é criada desde pequena para cuidar das pessoas e da casa, a maioria das meninas não vê a possibilidade de estar em outro parâmetro que seja diferente disso. Os brinquedos, as formas de se vestir são ditadas muito sutilmente em nossa sociedade. É muito fácil ver um menino brincar de "super-heróis", futebol, carrinhos de controle-remoto do que uma menina. Tal comportamento é considerado fora do padrão, julgado como errado e a criança que infringe tais regras sofre preconceitos. Evitar com que meninas brinquem com certos tipos de brinquedos dificulta a aprendizagem, promovendo o não desenvolvimento de conceitos de Física, Matemática, Computação e Automação, dentre outras. 


\section{REFERÊNCIAS}

ANDRADE, T. D. A família e a estruturação ocupacional do indivíduo. In: LEVENFUS, R. S. et al. Psicodinâmica da escolha profissional. Porto Alegre: Artes Médicas, 1997.

BORGES, E. P. Gênero, ciência e contexto regional: analisando diferenças entre os docentes da pós - graduação de duas universidades brasileiras. Dissertação (Mestrado em Ciência da Informação). Escola de Comunicação. Universidade Federal do Rio de Janeiro, Rio de Janeiro, 2014.

BRITO, C.; PAVANI, D.; JR, P. L. Meninas na ciência: atraindo jovens mulheres para carreiras de ciência e tecnologia. Revista Gênero, Niterói, v. 16, n. 1, p. 33-50, 2015.

CHASSOT, A. A ciência é masculina?: é sim senhora! São Leopoldo: Unisinos, 2003

CRUZ, F. M. L.; MAIA, L. S. L. Genialidade e loucura nas representações sociais do professor de matemática segundo estudantes e professores. Revista Práxis Educativas, Ponta Grossa, v. 6, n. 2, p. 235-247, 2011

CRUZ, J. O. Mulher na ciência: representação ou ficção. Tese (Doutorado em Ciências da Comunicação). Escola Comunicações e Artes, Universidade de São Paulo, São Paulo, 2007.

FINCO, D. Relações de gênero nas brincadeiras de meninos e meninas na educação infantil. Revista Pro-Posições, v.14, n. 3, 2003.

Socialização de gênero na educação infantil: fazendo gênero, corpo, violência e poder. Florianópolis, 2008.

LETA, J. As mulheres na ciência brasileira: crescimento, contrastes e um perfil de sucesso. Estudos Avançados, São Paulo, v. 17, n. 49, 2003.

LINS, B. A; MACHADO, B. F.; ESCOURA, M. Diferentes, não desiguais: a questão de gênero na escola. São Paulo: Reviravolta, 2016.

MATTOS, G. O.; SILVA, D. R. D; MOREIRA, J. A. A utilização de kits de robótica como ferramenta para o ensino de programação à meninas do ensino médio. In: XXIII WORKSHOP SOBRE EDUCAÇÃO EM INFORMÁTICA, 23., 2015, Recife. Recife, 2015.

PRÊMIO NOBEL. Disponível em: <http://www.nobelprize.org/>. Acesso em: 16 mar. 2017. 
QUEIROZ, C. T. A. P.; CARVALHO, M. E. P.; MOREIRA, J. A. Gênero e inclusão de jovens mulheres nas ciências exatas, nas engenharias e na computação. Recife: Universidade Federal Rural de Pernambuco, 2014.

SILVA, F. F; RIBEIRO. P. R. C. A participação das mulheres na ciência: problematizações sobre as diferenças de gênero. Revista Labrys Estudos Feministas, n. 10, 2011.

SOARES, T. A. Mulheres em ciência e tecnologia: ascensão limitada fundamental. Quim. Nova, v. 24, n. 2, p. 281-285, 2001.

Agradecimentos: Á direção e funcionários das Escolas Municipais, Estaduais e Particulares de Ouro Branco e Congonhas pela participação de suas alunas, confiança, disposição e parceira no projeto. As Secretarias de Educação das Prefeituras de Ouro Branco e Congonhas e a Câmara Municipal de Ouro Branco pela parceria. As (Aos) alunas(os) voluntárias(os) do CAP/UFSJ pelo apoio na execução do projeto. As professoras universitárias e colaboradoras pela participação nas edições do Greenlight for Girls. As colaboradoras do projeto IMCT, Ana Paula F. M de Urzedo, Ana Cristina M. M. Z. Armond, Mariana Garabini C. Hoyos, Ana Maria Resende. Á ONG Greenlight for Girls e Melissa Rancourt pelo apoio. As agências financiadoras Fapemig (2012), CAPES (2012), PROEXT (2013), PIBEX/PROEX/UFSJ (2016 e 2017), PROPE/UFSJ (Edital 008/2017) pelos recursos financeiros angariados para a execução destas ações.

Data de recebimento: 31 de julho de 2017.

Data de aceite para publicação: 19 de setembro de 2017. 